\title{
Five Gems in the Torrent: Historical Portrayals of Chinese Women in Sound and Religion
}

\author{
Yuchi Che
}

\begin{abstract}
In the long history of the patriarchal culture of China, women were consistently stigmatized as naïve. What made this situation worse was the mentality that-"a woman who lacks talent is a virtuous woman" 1 - a famous quote, which had became the standard to measure the qualities of a woman. This portrayal was quite permanent throughout the cultural history of China, as even today, this stereotype is still prominent in the poor, rural, and illiterate areas of China. This paper highlights in a chronological fashion the portrayal of the woman in the Chinese culture through sound, music, religion, and mythology.

KEY WORDS: China, woman, sound, religion, Communism, Nüwa, Pangu, Mulan, Confucianism, Lao Tsu
\end{abstract}

\footnotetext{
Coined by the Harvard feminist theologian Elizabeth Schüssler Giorenza, the concept of kyriarchy "denotes the power to dominate of those 'gentlemen' with property and education - heads of state, slave owners, and heads of households," and it is very applicable to the contemporary Chinese society. "Kyriarchy can best be theorized as a complex pyramidal system of super- and subordination, of exploitation and domination." In the Chinese society the portrayal of the woman through sound (including music) and religion (including mythology), has been quite derogatory. To reverse this cultural pattern, Su Zheng, in her work Redefining Yin and Yang: Transformation of Gender/Sexual Politics in Chinese Music, considers
} 
that it is logical and useful to apply the western ways of learning music and gender to the Chinese one since, as she believes, "each culture is not an isolated authentic entity waiting to be 'discovered' and added to the exotic palette of world gender ideologies." ${ }^{3}$

\section{1) The Beginnings}

In the Chinese cosmogony it is said that the universe was created by a male figure Pangu. After consuming all of his power, Pangu died leaving behind an imperfect world. The heaven did not completely cover the earth, and the earth did not hold the heaven all the way around its circumference. Due to this imperfection, a female figure Nüwa ${ }^{4}$ appeared, and as a mother figure, she took good care of everything left behind by Pangu; using the "five colored stones and legs of a tortoise" 5 to hold up the sky.

Apart from her role in the creation narrative, Nüwa is linked with the most ancient music of China. This most ancient music can be described as a primeval sound, since the ancient sources mention nothing about a particular song, except that Nüwa wished to create two musical instruments: the sheng, a reed pipe wind instrument, and the xiao, a vertical bamboo flute. ${ }^{6}$ Because Nüwa did not want to miss the magic of the universe, she created the musical instruments to catch the magic, and thus, both instruments are relevant to wind.

Nüwa is a mythological figure who cannot be placed into any tangible context. One can only recognize her spiritual role not only in the fixing of the imperfect universe and in giving humanity a new chance to live, but also in providing humanity with spiritual enjoyment. From this narrative the Chinese culture imagined that music had magic power, and the connection between humans and nature became allegedly more harmonious. Nüwa also served as a medium between heaven and earth; bringing the magic of heaven to earth for the spiritual benefit of the humans.

As Nüwa herself is a powerful figure, this myth reflects, at an unconscious level, the woman's position in the Chinese culture. Although she is considered important to fix the male figure's 
creation, she came second in the cosmogony narrative. By fixing and completing the creation left behind by Pangu, and by creating the two musical instruments, her motherly influence is crucial through her silence, self-sacrifice and devotion to humanity. Her appearance in the mythology undoubtedly shows us that the Chinese people believed that the feminine power represented also a dominant fixation of "muscular" power. They were indeed an organic part of the social life which was hard to be overlooked.

Yet, contrary to this mythical consciousness, in the Chinese history women continued to struggle to find their role as leaders in social life.

\section{Pre-Feudal Time}

Confucianism became the dominant value of feudal China, even though Confucius himself lived before China became a feudal country.

The most significant book of lyrics was edited by Confucius (551-479 BCE), and it is known as the Classic of Poetry (Shijing). The significance of lyrics and music holistically regarded as a unit is extremely significant as they often depended on each other, even though it was thought that the sound of music played a more important role than the lyrics. According to this book, the styles of the modes were divined into four types: Guofeng, Xiaoya, Daya and Song, ${ }^{7}$ and they all "all seem to have passed through the hands of men of letters at the royal Zhou court."8 What made the system very distinct and elitist is that people could only sing specific songs based on their social status. There was not pure entertaining in the art.

The Guofeng mode was an anthology of local ballads from different places of China, and from this aspect, only the plebeians were protagonists in the singing. On the other hand, both Xiaoya and Daya are radically different from Guofeng, since the character "ya" means orthodox in Chinese. It is not hard to understand why the singing was only for royalty, especially when the aristocrats went to meet the kings to offer their advice. 
There were no romantic songs in the part. The last part Song means ode, and these were dedicated to the praising of heroes and gods. This was the most serious one compared with Guofeng and Ya.

The Guofeng mode defined the social status of the woman. On the one hand, Confucius' misogynistic attitude toward women was already influential, particularly as he allegedly stated that, "only women and villains are hard to keep." In other words, women were no different from villains; or they were the villains that men feared. On the other hand, as a revered person, Confucius could not resist the beauty of femininity like all the other men without education. A song named Reed (Jian Jia) ${ }^{10}$ best describes Confucius' anxiety in this sense. From the category that the singing belongs to, it is easy to infer that there must have been many romantic elements within.

According to the newest archeological data, there were twentysix types of musical instruments used to accompany human voice. ${ }^{11}$ All of these were made from basic materials like bamboo, wood, and clay.

The lyrics of Reed is about a man who felt attracted by a beautiful woman who was playing at the riverside. Although he tried very hard, he failed to win her heart. His sentiments were expressed in the singing, which describe his excitement, anxiety, and disappointment. When singing with the aid of a natural musical instrument, the woman's pride was revealed.

The women's position in the pre-feudal China is a position of paradox. On the one hand, women were considered inferior to men since their gentle nature could not lead women to be as dominant as men. Yet, on the other hand, femininity was considered very important in sentimental terms. Unsurprisingly, in the long history of China, femininity was always praised by poets and writers.

For instance, in the very famous Chinese novel-Dream of the Red Chamber-Wang Xifeng was the model woman whose qualities included her being well respected, having rosy cheeks, a soft smile and "willow" waist, coming from a decent family. At the same time, the author described this woman as having an evil mind like a scorpion. 


\section{The Climax of Feudalism}

The story of the legendary Chinese warrior woman, Hua Mulan became highly popular in the Western World, particularly in America. Yet, in China, the most famous art form about Hua Mulan is a local opera named Yu Jv (opera of the Yu Province). Yu Province, serving as the cradle of Chinese culture, is the best representative of Taoism, one of the prominent Chinese religions.

In Taoism, it is said everything is made of two opposite elements-yin and yang - as well as various pairs of opposites such as high and low, easy and hard, existence and inexistence. ${ }^{12} \mathrm{At}$ the very beginning of his book, Lao Tsu stated that "existence is the father of heaven and earth; inexistence is the mother of everything. ${ }^{13}$ " When interpreting this text within the confines of Chinese culture and spirituality, the Chinese people tend to think everything in the world is made up of opposite elements. Compared with Confucius, Lao Tsu's values are more philosophical, as they tend to focus on the rules of the universe, while Confucius cares about morality and ethics.

As portrayed by the Yu Jv opera, the story of Hua Mulan serves as an organic explanation of Taoism. A woman born with her femininity, she had to hide who she was, and start behaving like a man with a "muscular" identity.

Starting with a dramatic bass, the opera presents through the singing that women are inferior to men. While performing, the singer is dressed in man's clothes while singing in a low pitch, in total contradiction to portrayal of the feminine in ancient China.
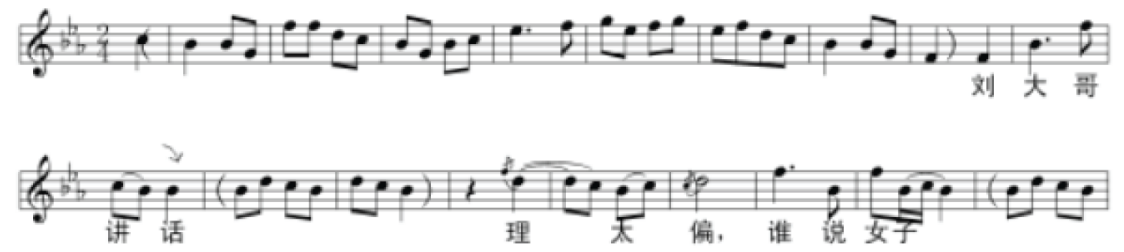

Example 1: Music score of Yu Jv Mulan (From http://www.zhaogepu.com/qita/180001.html) 
As the opera goes on, the tune and the pitch continue on this path. If a person who knows nothing about the story of Hua Mulan watches the opera, it is very likely to assume that Hua Mulan herself either misrecognizes her gender, or she is a transvestite. Although history portrays Hua Mulan as lacking femininity in the larger spiritual sense, it is not hard to predict that even with such a physical portrayal, physically she still looked very different from men.

Another gender issue in appears later in the Chinese opera. "During the first peak period of Chinese opera in the Yuan Dynasty (1271-1368), female performers took a leading role in the dramatic art and stage performances by playing both female and male roles."14 That is, there were no very obvious distinctions between a female role and a male role, and this well explains why the low pitch and the rhythmical singing are the main elements of the opera.

The end of the opera is a repeat of the start with the similar tune, pitch and lyrics that claim women are by no means inferior to men. Thus, after a person finishes listening to the opera, one might still meditate on gender equality. In ancient China, the existence of such an opera is a significant challenge to Confucius' misogynic values and caters more to Lao Tsu's deeper focus on the law of nature which creates everything.

Another condition that is very relevant to the opera Mulan is that at the same time, many other musical creations and drama reflect the same kind of "gender chaos." For instance, there was another opera in which a woman (Du Shiniang) commits suicide because her favorite man is too much of a coward to help her end her prostitution life which she hates. ${ }^{15}$ Another man dares not to challenge the rules of marriage and fails to marry Ying Ying, the woman who loved him. ${ }^{16}$ It is also important to highlight that the nomadic invasions, which at some point conquered China, brought nomadic values, as these operas did not appear until Genghis Khan conquered China. ${ }^{17}$ Thus, the traditional good Chinese gentlemen somewhat became cowards and feminine women had to turn to be like men to defend their territory and dignity. Hua Mulan was definitely a woman who had to make a choice to become like a man to save her own family. 
Thus, in terms of values promoted by Lao Tsu, one can notice how yin becomes yang, and yang becomes yin.

\section{Communist Time}

China did not become a communist country until 1949. However, once the Red Army settled in the Northern Shaanxi Province after the Long March, the Communist Party started to become stronger and stronger. ${ }^{18}$ By attracting people in the area to their ideology, and by calling people from other parts of China to join the movement, the communists started to draw attention of Nationalists, the party that aimed to build China into a capitalistic country. The challenges from the Northern Shaanxi Province-particularly the harsh economic and unpleasant natural conditions-were taken up by communists as a challenge to feed the population. As a first step, they focused on converting the wasteland into farmland, so that the communist revolution could continue to solidify, a process that triggered the "Great Production Movement."19 It is evident that people had to be physically strong so they could produce more wheat, and the women - though physically very different from men-were required to act like men in terms of performing equal type of labor.

The music of the time was a great reflection of "anxiety." The Haozi (Work Song) - a type of singing for the working class performed during labor-was aimed to make all the people pull or push something together as a watchword, ${ }^{20}$ and consequently became a very popular style performed on the stage.

As part of China's agrarian history, this kind of singing that was familiar to everyone. However, what made it special this time was that the most "vulgar" culture was transformed into a high culture, which served as the symbol of the new intelligentsia and elite. What was even more ironic was that the "vulgar" culture was now a symbol for the entire nation, all the people, especially for the new elite.

In a sense, what was performed on the stage was a reemergence of what had happened in the field. Some of the singing started with very strong mobilizing words like, "one, two, three," which sounded no different from the natural yelling on the field. 
When performing on the stage, women were wearing the same kind of colorless cotton clothes as men, and the aim of the clothes was to find the sameness of two genders, which is the absolute masculinity. ${ }^{21}$

Several kinds of working songs were popular in different parts of China, and because the north of Shaanxi Province is very dry and mountainous, there are no working songs highlighting activities such as fishing. The dominant themes include songs related to field work and spinning, which only women sang.

The spinning working songs were less muscular compared with field songs. Thus women had a chance to make people know what they did through the art form. In ancient China, women only spun at home, and a positive aspect of Great Production Movement was that it praised the work of the women and made them more respected inside the society.

The emotion of spinning working songs was usually very perky. One woman started the song by singing "let's start spinning," and the other ones would follow singing "yes, let's start spinning." Beginning with laughter, all women proceeded to imitate the sound of spinning machines, and sang how happy they were when doing their work. ${ }^{22}$

It's very easy to notice the dramatic aspect of the songs, as the emotions are particularly fake. Though working was generally received as a positive experience particularly for the development of agriculture, the determination to eliminate a women's femininity is noticeable in every song.

\section{Post-Cultural Revolution}

The Chinese people admitted that the Cultural Revolution was rather a negative experience in the history of China. The direct result of the movement was the death of the countless educated people, including artists. ${ }^{23}$ Since the aim of the Cultural Revolution was to develop a "practical" technology, art was considered useless and Mao ordered to be eliminated from the educational system. ${ }^{24}$ Thus, in the process of the cultural development, a cultural faultage 
followed, as the new generation came to create a new culture, and had to face this problem.

Although there is no such a concept as "post Cultural revolution"-similar to the concept of "post-modernism," I will use this in a conventional sense to describe the cultural situation which followed the cultural faultage. The Chinese people started confessing all the mistakes that have been made during the Cultural Revolution, and the trade between China and other countries ${ }^{25}$ led to economic prosperity which impacted the musical field as well. The impact upin music and the portrayal of women can be described as cultural progress indeed as female singers played a very important role in the music industry. On one hand, the women's femininity came to life again, and on the other hand, some women expressed their dissatisfaction with expressing themselves in the patriarchal society, and chose to do something new and challenging. Thus, the double aspects were like a paradox, which dragged women in two opposite directions.

Among the conservative group, several female figures became prominent in the popular culture as they chose to conquer the world with their soft-voiced singing style. The themes of their songs were mainly about love and romance between men and women. As this style of music-prominent during feudal China-had been hidden for a long time, since during communism, women had to suppress their femininity.

During this time, several female singers from Taiwan and Hong Kong became popular in mainland China. The most famous singer of the time was Deng Lijun. In a sense she became a milestone in post-Cultural Revolution period through her love songs and children songs. For instance, one can see the explanation of femininity through the names of several songs: (Your Smile is) as Sweet as Honey, You Are the Only One That I Care About, Miss Rose, the Love Song of the Peninsula, etc. The smooth flowing of this soft singing of the tune is much admired by the Chinese popular culture.

Another trend of singing style was promoted by women who were courageous enough to import various patterns from the western culture. It took great courage because China was a conservative country and everything that was different from 
traditional Chinese culture was generally despised and rejected at the beginning, including musical instruments.

A female singer named Cheng Fangyuan took the most challenging western elements home. When being interviewed, Cheng sincerely expressed how excited and surprised she was when watching the show of English musical band Wham!, ${ }^{26}$ which was the first western music band allowed to perform in China after 1978. As she was shocked by the "crazy" dancing and volume of music in its performance, she understood the passion that was flowing in the veins of Chinese young generation. Thus, she led a musical revolution in China. Guitar, a musical instrument that had never been heard of by Chinese people, was introduced onto stage by Cheng. She not only played the guitar, but also sang some western songs in Chinese. For instance, she brought the Lonely Goatherd from the Sound of Music to Chinese stage. For the first time, the Chinese people heard yodeling. Even today Chinese people can still sing the tune "Lay yi yo lay yi yo lo". The western style of singing made this woman a cultural icon in China, and her identity in China was unchallenged. Several male singers even followed her to start their rock and roll.

Since the beginning of the twentieth century the Chinese people started to be influenced by European cultural ideas, but during Mao's ruling, China became isolated from the rest of the world for many years, and the Chinese people thought they lived at the center of the world as their ancestors did hundreds of years ago. However, as soon as China opened its doors in 1978, the Europe-centric ideas had been adopted again by the Chinese people.

Yet, the interest in the European values had its own mishaps. With the New Cultural Movement that started in 1919, the Chinese scholars began to reject Confucianism; a philosophy that stood at the foundation of the Chinese culture. By rejecting Confucianism which was an organic part of the Chinese culture, and by superficially adopting European values, a cultural vacuum was created. The society itself lost its moral compass, as people had no rules to follow to regulate themselves. For instance, while rejecting the "parentsarranged" marriages, the young generation did not have a real understanding of the western culture either. 
This instability was reflected in Chinese music as well. Music was no longer a pure form of art, but became a part of cultural industry that involves sensual elements. This was intensely criticized by Adorno and Horkheimer in their The Dialectic Of Enlightenment. Unlike Cheng, many female singers adopted the negative aspects of western music rather than the positive aspects of music itself, while female singers chose to wear less and less clothes during their musical performance. Clothing had nothing to do with music itself, but served as a tool in measuring their "success" on the stage. On the negative side, this reality undermines the art of music itself, as artistic creativity is overshadowed by frivolousness. European culture is beautiful in itself, but these singers failed to adopt its beauty.

At the beginning of this trend, the female singers were extremely reluctant to use any morally compromising lyrics in their songs, but as the industry grew along with the desire for chasing wealth, the younger singers had to reconsider their convictions and even renounce traditional values.

A Chinese minority girl Jike Junyi with brown skin color came into Chinese people's attention not only through her physical appearance which is different from majority Chinese, but also because her new-styled rapping. To gain the popularity she hopes for, Jike Junyi imported the Snoopy Dog character from America to perform next to her while she is singing on the stage. Jike Junyi is also trying to imitate Nicki Minaj not only in singing, but also through the clothing she wears and through the display of female sensuality. Contrary to the traditional Chinese culture which values white skin color, Junyi's dark skin makes her particularly appealing on her path to success.

\section{Conclusion}

As I conclude my paper, and as a woman, I cannot but feel emotional about the saga of the female portrayal through sound and religion in the cultural memory of my native China. The myth of Nüwa from the Chinese cosmogony continued to inspire the Chinese woman 
as someone who not only completes and solidifies what a man is unable to finish, but also makes room for artistic expression and beauty. Nevertheless, the historical trends that inhibited, derided and even incriminated the values that make the Chinese woman unique seem to continue though cases such as Jike Junyi. As the cultural history of humanity is a dynamic process, the current phenomenon of globalization is an experiment in progress with unanticipated consequences on how Chinese women will react in the future when positioning themselves in the torrent of history.

\section{NOTES}

1 清·张岱《公祭祁夫人文》。Gong Ji Qi Fu Ren Wen was written by Zhang Dai in Qing Dynasty. As this book was written about four hundred years ago, this expression has become part of the popular culture; therefore specific bibliographic referencing unnecessary.

${ }^{2}$ Elizabeth Schüssler Fiorenza, Political Theology, (Louisville: John Knox Press, 2013), 26.

${ }^{3}$ Su Zheng, "Redefining Yin and Yang: Transformation of Gender/Sexual Politics in Chinese Music," in Audible Traces: Gender, Identity, And Music. eds. Elaine Barkin and Lydia Hamessley (Zürich and Los Angeles: Carciofoli Verlagshaus, 1999), 154.

${ }^{4}$ 山海经. Shan Hai Jing(in Chinese). 4th Century BC. Since this is book written more than one thousand years ago, thus, I cannot find a specific publisher and a page number.

${ }^{5}$ Ibid.

6 《史记·补三皇本记》：““娲氏风姓, 有神圣之德, 代密仪、立号 日女希氏，作笙黄。”此时的笙簧以竹、木片制. Shi Ji, an ancient Chinese history book. Since there's no English version, I use Pinyin here to name the instruments.

${ }^{7}$ I consider the different names as common sense since we learned this in middle school, and there is no specific book served to quote.

${ }^{8}$ Hans H. Frankel, The Flowering Plum and the Palace Lady, (New Haven and London: Yale university, 1978), 215.

${ }^{9}$ Confucius, The Analects, Chapter 17. Sentence in Chinese: 唯女子与小人 为难・ 也, 近之则不逊, 远之则怨。

${ }^{10}$ Name in Chinese: 萐臀

${ }^{11}$ Wang Xianqian, Shi San Jia Yi Ji Shu Beijing: Zhong Hua Shu Jv Press, 1987)。王先谦 : 诗三家义集疏。

${ }^{12}$ Lao Tsu ,Tao Te Ching, chapter 2.

${ }^{13}$ Ibid. 
${ }^{14} \mathrm{Su}$ Zheng, "From Chinese Woman Composer Hsiao Shusien to the Role of Women in Chinese Music," paper presented at "A Festival of Sino-American Music and Culture," University of Cincinnati, Cincinnati, Ohio (March 1996).

15 杜十娘怒沉百宝箱 (Du Shiniang Sinks Her Treasure Box Angrily.)

${ }^{16}$ The Story of the West Wing.

${ }^{17}$ Genghis Khan conquered China around 1265.

${ }^{18}$ The Long March took place between 1934 and 1936. This data is recalled from what we were taught in high school history classes.

${ }^{19}$ This is my own translation into English, since there is no official version. The official Chinese name is Da Sheng Chan. 大生产。

${ }^{20}$ I read the introduction of the art online since I don't find any systematic introduction books, and moreover, the art form is a part of Chinese people's life. Thus, the name is gained through life experience rather than academia.

${ }^{21}$ I watched this from Dong Fang Hong (The East Is Red) show.

${ }^{22}$ From the song named Great Production of Army and Farmers. 军民大生 产.

${ }^{23}$ Based on the list of the death during Cultural Revolution from http:// zh.wikipedia.org/wiki/ 文化大革命受難者列表. (Last accessed on April 2, 2016)

${ }^{24}$ Down to the Hill Moment was advocated by Mao during late1960s to early 1970s.

${ }^{25}$ Chinese economic reform advocated by President Deng Xiaoping in 1978.

${ }^{26}$ The interview can is available online at https://www.youtube.com/ watch?v=lvXZSeuHY7U (Last accessed on April 2, 2016). 